\title{
Law Students' Memories of a Crime Scene: Does the Practice of Memorisation and Recitation Matter?'
}

\author{
By Samia A. M. Hassan* \\ Ahmad H. Mustafa ${ }^{\dagger}$ \\ Khadija El Alaouit \\ Maura A. E. Pilotti ${ }^{+}$ \\ Khadijah Aldabbagh ${ }^{\circ}$ \\ Sahar Zaghaab
}

\begin{abstract}
Because memory is inherently reconstructive, individual differences in the accuracy of eyewitnesses' recollections exist. In the present study, we investigate one source of accuracy, rote rehearsal training (i.e., memorisation and recitation), which is a key aspect of educational and religious practices in the Kingdom of Saudi Arabia. In the study, male and female law students witnessed a staged crime. It consisted of an unknown person of the same gender unexpectedly entering a classroom where the students were in attendance, grabbing the instructor's bag, and quickly leaving without saying a word. Immediately afterwards, students reported the details of the scene they witnessed as well as their use and views of rote rehearsal. Overall, recollection rates were less than optimal for static details of the perpetrator, but improved for details of actions. Witnesses who rejected misinformation recollected more accurately the perpetrator's behaviour as well as broad static details, and were more confident in their memories than those who failed to reject misinformation. However, recollection was not associated with any of the performance indices of reliance on rote rehearsal. Discussion focuses on the extent to which this specialised training is practiced and may not be transferable to memory for complex visual scenes.
\end{abstract}

Keywords: Illusory memory; Memorisation practice; Individual differences; Explicit memory.

\footnotetext{
${ }^{1}$ Corresponding author: Dr. Maura A. E. Pilotti, email: mpilotti@pmu.edu.sa

"PhD, Assistant Professor, Department of Law, College of Science and Human Studies, Prince Mohammad Bin Fahd University, Al Khobar, Kingdom of Saudi Arabia

${ }^{\dagger} \mathrm{PhD}$, Assistant Professor, Department of Law, College of Science and Human Studies, Prince Mohammad Bin Fahd University, Al Khobar, Kingdom of Saudi Arabia.

"Ph.D., Assistant Professor, Department of Humanities and Social Sciences, College of Science and Human Studies, Prince Mohammad Bin Fahd University, Al Khobar, Kingdom of Saudi Arabia.

${ }^{+} \mathrm{PhD}$, Assistant Professor, Department of Humanities and Social Sciences, College of Science and Human Studies, Prince Mohammad Bin Fahd University, Al Khobar, Kingdom of Saudi Arabia.

Undergraduate Student and Research Assistant, College of Science and Human Studies, Prince Mohammad Bin Fahd University, Al Khobar, Kingdom of Saudi Arabia.

PhD Candidate, Lecturer, Department of Law. College of Science and Human Studies, Prince Mohammad Bin Fahd University, Al Khobar, Kingdom of Saudi Arabia.
} 


\section{Introduction}

A wealth of evidence collected from the early stages of scientific inquiry to the present has made the reconstructive nature of human memory an undeniable fact. Bartlett ${ }^{2}$ was one of the first to note that veridical recall is less than reliable. Specifically, he reported that the recall of an unfamiliar story that people read once became less veridical, including more fragmentary, impoverished, and distorted, as a function of the passage of time. Of course, he did not find that participants forgot the main theme of the story, but rather that they changed or omitted some key details to suit their expectations and pre-existing knowledge.

Although it is now common knowledge that distortions, including omissions and additions, increase with the passage of time in predictable manners based on prior learning and expectations, time cannot be considered the only culprit of documented discrepancies between people's memory of past events and the actual events. Distortions also occur when memory is tested immediately after the encoding/acquisition phase, depending on the extent to which the newly acquired information activates pre-existing knowledge and expectations (i.e., relatedness) ${ }^{3}$, as well as is influenced by the context of retrieval (e.g., misleading inquiries ${ }^{4}$ ). Nowhere evidence of distortions is more plentiful and relevant than in research on eyewitness testimony. ${ }^{5}$

\section{Literature on Illusory Memories of Eyewitnesses}

Eyewitness testimony refers to the content of a formal report that a witness to a crime is required to convey to police, judges, lawyers, and, in some judicial systems, juries. Because the report is often used to identify the culprit(s) of the crime and assess his/her degree of responsibility, accuracy is of paramount importance. Scientific studies of eyewitness testimony have documented its weaknesses, including selectivity, poverty of critical details, misrepresentation of facts based on viewing conditions and witnesses' state of mind and expectations, as well as susceptibility to misleading information provided after the crime has occurred. ${ }^{6}$ The latter phenomenon is the one that has captured the interest and attention of scientists, practitioners of the law and even laypersons, due to its surprisingly widespread nature and the availability of sensible remedies. Nevertheless, distortions arising from the way people process unexpected events in their environment cannot be discounted as minor hiccups. ${ }^{7}$ In fact, memory content not only can be shaped by post-facto information, such as a misleading question, but also by older memories that are automatically activated in witnesses' mind while an event is experienced. ${ }^{8}$ Automatic activation is driven by the

\footnotetext{
${ }^{2}$ Bartlett (1932).

${ }^{3}$ Gallo ( 2010).

${ }^{4}$ Loftus (2003).

${ }^{5}$ Loftus (2003); Wells (1993); Wells \& Olson (2003).

${ }^{6}$ Lacy \& Stark (2013).

${ }^{7}$ Lacy \& Stark (2013).

${ }^{8}$ Kuhl, Shah, DuBrow \& Wagner (2010).
} 
similarity or mere association between an older memory (e.g., past co-occurrences of gun - mustache) and a current event (e.g., gun - beard), which leads to interference between past and present. As a result, expectations, based on prior knowledge, become capable of shaping the encoding of new information into human memory, thereby reducing the accuracy of memories of new experiences. Another threat to memory accuracy is the repeated retrieval of an event, which is a common occurrence if the event is a crime, due to its relevance to the witness and/or to the people with whom he/she interacts. ${ }^{9}$ Of course, it is reasonable to expect memories of mundane events to become fragile and susceptible to a greater degree of distortion as time goes by, since analogous experiences are likely to accumulate, and the unique features of the original events may fade into oblivion. Emotional, or even traumatic events (e.g., a crime), albeit distinctive, tend to be particularly prone to distortions by information that becomes available in the intervening time (e.g., attention to media reports, comments made by individuals to whom the event is narrated). ${ }^{10}$ Even if the impact of retelling an event multiple times to different audiences is discounted, the arousal that defines it is unlikely to benefit memory accuracy, often leading to improved memory for the gist of the event (e.g., witnessing a robbery) as well as depleted memory of details (e.g., the clothing of the robbers). ${ }^{11}$

Not surprisingly, given the evidence reviewed above, true and false memories cannot be clearly distinguished through inspection of patterns of brain activity. In fact, although overall true memories tend to contain more sensory details than false memories and the latter demand more activity in the prefrontal cortex during encoding and retrieval, ${ }^{12}$ the processes that lead to true and false memories are largely overlapping. With the passage of time between witnessing an event and having to describe it to the police or in court, content-related differences tend to evaporate. Most troubling, witnesses are often confident in the accuracy of their recall of a past event, thereby overlooking the potential weaknesses of the memory upon which their testimony relies. ${ }^{13}$

According to Loftus, ${ }^{14}$ people's memories are the records of not only their past actions, but also their thoughts, beliefs, and any information provided by others (i.e., social influence). Thus, one may ask whether individual differences in memory accuracy exist. To answer this question, researchers have focused on either dispositions ${ }^{15}$ or demographic characteristics as placeholders of diverse life experiences and training. ${ }^{16}$ For instance, Eisen, Morgan, and Mickes ${ }^{17}$, who examined human dispositions, reported that suggestibility to misleading

\footnotetext{
${ }^{9}$ Wiltgen \& Silva (2007); Winocur, Moscovitch \& Sekeres (2007).

${ }^{10}$ Hirst et al. (2009).

${ }^{11}$ Christianson \& Loftus (1987); Loftus \& Burns (1982).

${ }^{12}$ Gutchess \& Schacter (2012); Rissman, Greely \& Wagner (2010); Slotnick \& Schater (2004); Stark, Okado \& Loftus (2010).

${ }^{13}$ Hirst et al. (2009); Kassin, Tubb, Hosch \& Memon (2001); Odinot, Wolters \& van Koppen (2009); Simons \& Chabris (2011).

${ }^{14}$ Loftus (2003).

${ }^{15}$ Mills \& Lynn (2000).

${ }^{16}$ Loftus, Levidow \& Duensing (1992).

${ }^{17}$ Eisen, Morgan \& Mickes (2002).
} 
information is related to acquiescence, a cognitive style that embodies the tendency to agree with a variety of statements even if they display opposing contents. Acquiescence, however, was not found to be related to memory accuracy when no misleading information was present. Meyersburg, Bogdan, Gallo and McNally ${ }^{18}$ reported magical ideation (i.e., beliefs in unconventional modes of thinking and being) and absorption (i.e., rich imagination) as dispositions that characterise individuals who not only exhibit high levels of false recall and recognition of lists comprised of semantically associated words, but also report improbable memories of past lives. Similarly, higher false recollection rates, along with elevated absorption, magical ideation, and symptoms of depression, were found by Clancy, McNally, Schacter, Lenzenweger, and Pitman ${ }^{19}$ in individuals who report having been abducted by space aliens. Instead, Loftus et al., ${ }^{20}$ who examined demographic variables such as gender, age, educational level, and occupation as a function of memory accuracy with and without misleading information, found that eyewitnesses were more accurate in their recollections the higher was their education level. Some occupations (e.g., being a teacher, sales person, artist or architect), were associated with increased memory accuracy compared with other occupations (e.g., being a lawyer or in law enforcement). However, a higher educational level was not related to lower susceptibility to misinformation (i.e., suggestibility). Moreover, artists and architects who were reasonably accurate when no misleading information was present were found to be highly susceptible to such information when it was subtly communicated to them. Similarly, Loftus et al. ${ }^{21}$ reported that accuracy did not differ between males and females when no misleading information was present, but that males were more often mislead than females. Loftus et al. ${ }^{22}$ also found that middle-aged individuals were more accurate and less suggestible than children and older adults.

Although some evidence of individual differences in memory accuracy, including susceptibility to misleading information, exists, the link between specific demographic characteristics and memory accuracy remains less intuitive than those involving specific dispositions. Demographic characteristics, such as type of occupation, merely create separate categories of individuals whose specialised training and experiences are then scrutinised to determine how they can account for the presence or absence of documented group differences. Results of this type of approach tend to be rife with inconsistencies ${ }^{23}$ as they postulate noticeable qualitative and quantitative differences in training and experience between groups, but often overlook within-group differences as well as the precise link between the actions and skills practiced by some groups relative to others and the memory processes that such practice allegedly benefits. Interestingly, a specific demographic characteristic that arises from educational and religious customs of the Middle East, which is the practice of memorisation (i.e., rote rehearsal of

\footnotetext{
${ }^{18}$ Meyersburg, Bogdan Gallo \& McNally (2009).

${ }^{19}$ Clancy, McNally, Schacter, Lenzenweger \& Pitman (2002).

${ }^{20}$ Loftus et al. (1992).

${ }^{21}$ Loftus et al. (1992).

${ }^{22}$ Loftus et al. (1992).

${ }^{23}$ Ainsworth (1981); Loftus et al. (1992); Tickner \& Poulton (1975); Yuille (1984).
} 
information to be committed to long-term memory) and recitation (i.e., rote rehearsal to preserve information in long-term memory), offers a more intuitive link between the contents of real-life training and memory accuracy. Furthermore, because individual differences in frequency and mode of use (performance measures) as well as views (sentiment measures) exist, a within-subjects approach can be used to determine whether memory accuracy is associated with either the exercise or views of the practice of memorisation and recitation.

Although rote rehearsal is often judged as a poor learning strategy in the Western world, the exercise of repeating information is a popular tool in the Middle East used not only to merely commit information to memory (i.e., naql), but also to make information accessible to elaborative processes, including understanding, critical analysis, and problem solving (i.e., ' $a q l$ ). ${ }^{24}$ Important to note is that this custom is not limited to religious instruction. On the contrary, it encompasses memorisation and recitation of oral poetry, which predates the use of memorisation and recitation in traditional Islamic schooling and has shaped mainstream educational practices in the Middle East. ${ }^{25}$ The widespread use of memorisation and recitation is not a surprising phenomenon. Evidence exists that repetition can enhance the amount of information remembered. ${ }^{26}$ In addition, extensive rote rehearsal practice has been found to induce metabolic and morphological changes that underscore enhanced functioning in hippocampal areas. $^{27}$ Taken together, these findings suggest that the extent to which such practice has been exercised may be related to memory accuracy, defined both as superior recollection rates for information actually presented and as low rates for information incorrectly believed to have been presented (false recollection).

\section{Rationale of the Present Study}

To our knowledge, the relationship between experiences with rote rehearsal practice (including frequency and personal views) and memory of unexpected and complex visual scenes (i.e., a staged crime) has yet to be examined. Thus, the goal of the present study is to assess whether the accuracy of eyewitnesses' recollections of an unexpected event (i.e., a staged crime) can be predicted by their experiences with rote rehearsal practice. Accuracy refers to eyewitnesses' recollection of central details of the physical appearance of the alleged perpetrator and his/her behaviour, as well as their responses to a misleading suggestion (i.e., questions regarding a fact that did not occur during the staged crime). Law students in the Kingdom of Saudi Arabia (KSA) are selected to be the eyewitnesses because law students tend to have a keen interest in memory accuracy exercised through heavy reliance on rote rehearsal, both as a technique to acquire verbal information (i.e., memorisation) and as a technique to retain such information in long-term memory (i.e., recitation). Thus, above and beyond past use of rote

\footnotetext{
${ }^{24}$ Iqbal \& Ahmad (2015); Al-Ghazali (2011); Günther (2003).

${ }^{25}$ Gade (2004).

${ }^{26}$ Dunning \& Stern (1992); Hintzman (1976); Scrivner \& Safer (1988); Turtle \& Yuille (1994).

${ }^{27}$ Hartzell et al. (2016); Roche et al. (2009); Valenzuela et al. (2003).
} 
rehearsal, which is promoted by dominant religious customs as well as pedagogy in primary and secondary education, law students actively practice it. As in all forms of extensive and effortful training, it is reasonable to expect variability in the frequency of the practice of rote rehearsal and in the extent to which it is used in conjunction with elaborative rehearsal. As such, law students are thought to represent an ideal group for studying the extent to which variability in deliberate rote rehearsal training relates to memory inaccuracies and susceptibility to misinformation. Yet, law students' memory training mostly encompasses the verbal sphere, whereas the content of eyewitnesses' memories largely refers to both static and dynamic details of often complex visual scenes. Thus, it is hypothesised that if the verbal memory training, which law students have undergone in their day-to-day endeavours, impacts their more general information processing skills, including attention to details, then a positive correlation will be found between frequency of practice and memory accuracy (i.e., percentage of details of a crime scene remembered, and likelihood of rejection of misleading post-event suggestions). A correlation is also expected between students' views of rote rehearsal practice and memory accuracy since beliefs in the effectiveness of an effortful practice ${ }^{28}$ can shape not only the frequency, but also the character of its use. ${ }^{29}$ Incidental (i.e., without forewarnings) recollections of a staged crime (i.e., snatching of a professor's bag in a classroom) are tested immediately after its occurrence to capture as closely as possible real-life experiences of an unforeseen event and the initial memory records developed as a result of such experiences.

\section{Method}

\section{Participants}

Participants were 174 law students of Prince Mohammed Bin Fahd University (PMU), a private university adjacent to the urban centres of the Eastern Region of KSA. There were 91 females and 83 males whose age range was 18-25. Students were Arabic-English bilingual speakers who considered Arabic as their first language, and English as their second language. Prior to admission, students demonstrated English language proficiency through standardised English proficiency tests (i.e., Aptis, IELTS, or TOEFL). As a second language, English was typically learned as a school subject, and was reported to be the mode of instruction in selected classes at PMU, as well as used as a communication and information-gathering tool in and outside the classroom. For these students, as for most young residents of the urban centres of the Eastern Region of KSA, exposure to English and Western customs could be said to coexist with Arabic and Islamic customs, which remain the keystones of socialisation practices of KSA youth.

\footnotetext{
${ }^{28}$ Hasher \& Zacks (1979).

${ }^{29}$ DeKeyser (2007); Paris (1997); Scarborough, Gerard \& Cortese (1979); Schwarz \& Büchel (2015).
} 


\section{Procedure and Materials}

A crime was staged in a classroom. The entire event lasted less than a minute. It consisted of a person unknown to students who suddenly entered the classroom where students were listening to a lecture of a law professor. The room was generally well lit to ensure that eyewitnesses could detect even fine-grained details of the crime scene. Due to gender segregation rules, the unknown person, serving as the perpetrator, was a female in classes of female students, and a male in classes of male students. Thus, male students witnessed a staged crime executed by a male culprit, whereas female students witnessed the same crime executed by a female culprit. He/she quickly walked to the desk where the professor's personal items, including a bag (i.e., a handbag for the female faculty and a suitcase for the male faculty) rested. The pseudo perpetrator grabbed the bag and, at the same walking speed, left the room. The professor assumed an expression of surprise, but did not otherwise react to the event. The culprit neither interacted with the professor nor exchanged eye contact. Fourteen law classes were tested, ranging in size from 10 to 26 students.

Immediately after the crime was staged, two questionnaires were distributed to the students who served as eyewitnesses to the alleged crime: one devoted to the assessment of eyewitnesses' memories and one intended to gather information about students' reliance on and views of rote rehearsal, including memorisation and recitation practices. In both questionnaires, each question was written in both English and Arabic to encourage students to report their answers in their preferred language.

The eyewitness questionnaire asked students to report their recollection of the unexpected event they witnessed. The questionnaire contained 34 questions. Descriptive queries required witnesses to report the perpetrator's behaviour ( $n=6$; e.g., what did the offender take?), fine-grained physical characteristics $(n=6$; e.g., what was the colour of his/her eyes?), and broad physical characteristics ( $n=6$; e.g., what outfit did the person wear?). Other queries focused on the psychological or physical state of the witness ( $n=5$; e.g., during the event, were you distracted? Were you unwell?). Two questions asked about the voice of the perpetrator even though the alleged culprit never uttered a word during the entire staged crime scene (misleading items). The first was placed at the start of the questionnaire ( $7^{\text {th }}$ item) and simply asked whether the perpetrator said anything. The other was placed towards the end ( $31^{\text {th }}$ item) to determine whether the earlier minor suggestion became a memory. It asked whether there was anything noteworthy about the voice of the offender. Filler questions $(n=9)$, spread throughout the questionnaire, were intended to assess respondents' intention to comply with the instructions. Thus, they contained requests to either report obvious background/ peripheral properties of the scene ${ }^{30}$ (e.g., time and location of the event) or estimate central information of the scene (e.g., approximate height and age of the perpetrator).

Descriptive queries always referred to central characteristics (i.e., integral to the unexpected event). Broad (i.e., easily detectable) static details included overall

\footnotetext{
${ }^{30}$ Migueles \& García-Bajos (1999).
} 
shape of face and body (to be identified from silhouettes), hair colour, skin colour, and type of outfit (to be described in writing). Fine-grained static details included colour and shape of eyes, shape of eyebrows, nose, and mouth, and hair texture (all to be identified from silhouettes). Queries about movement required information about how the alleged perpetrator entered and left the room, the object he/she took, how he/she took it, and the duration of the entire scene (to be described in writing). Multiple choice questions were used in the section devoted to the physical characteristics of the alleged culprit to guide participants to produce concrete answers whose accuracy could be easily determined by rates through comparison with pictures of each culprit taken before the staged crime. Furthermore, questions regarding the physical characteristics of the perpetrator tended to offer choices in the form of sketches if pilot work had indicated that spontaneous verbal descriptions would be likely to be imprecise and scant without further prodding to clarify content. For instance, a question about the body shape of the perpetrator was accompanied by four silhouettes, only one of which unequivocally corresponded to his/her body shape. Of course, there was a different set of silhouettes, depending on whether the perpetrator was a male or a female. All descriptive questions inquired about true characteristics/aspects of the staged event with the exception of two misleading questions, both of which referred to a feature of the perpetrator's behaviour that could not have been observed. Questions pertaining to the self-assessment of the witnesses' state included being frightened, tired, preoccupied, distracted, and unwell, all to be estimated on a 7-point agreement scale from 0 (very untrue of me) to 6 (very true of me) with 3 being the neutral point. The average of the evaluations of witnesses' emotional and physical states was computed to serve as an overall measure of attention devoted to the staged crime. The higher the score, the more inattentive the eyewitness was estimated to be.

Each question, irrespective of whether it was open-ended or multiple choice, was always followed by a 5-point scale requesting students to report their level of confidence in the answer provided from 1 (not confident at all) to 5 (extremely confident). A statement appeared at the end of the questionnaire asking students to list anything that they wanted to report of the event they witnessed, but had not been asked through the preceding questions.

The second questionnaire surveyed rehearsal practice by asking students to report their experiences with memorisation (i.e., rote rehearsal used to add information to long-term memory) and recitation (i.e., rote rehearsal used to preserve information already in long-term memory). Experiences were organised into two categories: performance $(a, b, \& d)$, and sentiment $(c)$. Specifically, they involved $(a)$ frequency of use of rote rehearsal in students' past (e.g., primary and secondary school) and current education (i.e., college), to be recorded on a scale from 1 (never) to 5 (always); (b) breadth of use (e.g., employed to encode isolated words and/or sentences), (c) perceived effectiveness, either as the estimated duration of memories created through rote rehearsal, which was to be reported on a 9-point scale from 0 (none) to 9 (a year or more), or as an opinion about the mode of use, to be selected from four options (i.e., ineffective alone, no opinion, effective alone, or effective with understanding) numerically coded from -1 to +2 . 
Questions regarding the amount of the Quran memorised and the frequency of recitation in religious practices were also included $(d)$. It was recognised that memorisation and recitation of holy texts are key tools in Islamic religious customs, which shape students' everyday life since early age, and whose application goes well beyond the educational sphere. Religious rituals consist of the memorisation and periodic recitation of verses of the Quran and of Prophet Muhammad's Hadith. Thus, limiting questions to the educational sphere would not have captured the full extent to which memorisation and recitation are exercised and valued.

Prior to data collection, face and full body pictures were taken of the alleged culprit wearing the outfit later used to stage the crime. For both male and female culprits, the outfit consisted of a t-shirt, pants, and closed-toe shoes in subtle shades. Either outfit was chosen to look conventional in either all-female or allmale settings. In addition, each culprit was asked to describe his/her physical appearance by filling out the section of the eyewitness questionnaire that students used to describe the culprit after witnessing the staged crime. An independent rater examined the pictures of the culprits and filled out the same section of the eyewitness questionnaire. Then a third rater compared the two sets of responses for each culprit to ensure an agreed-upon description of the offender. The latter, which constituted the standard description of the perpetrator, was used to assess the extent to which students' identification of the culprit was accurate.

\section{Results}

Participants' compliance with the instructions to recollect the staged event was demonstrated by their providing sensible (if estimates were required) and accurate (if descriptions were required) answers to filler questions. Thus, answers to the other sections of the questionnaire could be analysed for accuracy. For each participant, the recollections of the physical (i.e., static) details of the perpetrator were coded as correct or incorrect. Then the percentage of fined-grained details and the percentage of broad details correctly remembered were computed. The same procedure was utilised to code each participant's recollection of the behaviour of the perpetrator during the staged crime scene and then compute the percentage of details correctly remembered. Lastly, each participant's sensitivity to misleading information was coded as his/her failing to reject at least one of the misleading inquiries about the perpetrator's verbal behaviour.

Descriptive statistics of the eyewitness questionnaire are reported in Table 1. In the table, each set of questions is accompanied by the percentage of correct answers along with the average confidence with which participants reported such answers. In addition, the extent to which participants agreed with each of the statements regarding their state during the observation of the crime is reported along with their confidence in such responses. Table 2 displays the data of the rehearsal practice survey. 
Table 1. Participants' Responses to the Eyewitness Questionnaire (Standard Error of the Mean in Parentheses)

Category of Questions

Identification of Perpetrator

Fine-grained Characteristics

(IPFC)

Broad Characteristics (IPBC)

Behaviour (IPB)

$\begin{array}{ll}\text { Mean Accuracy } & \text { Mean Confidence } \\ \text { Scale: } 0-100 & \text { Scale: } 1-5 \\ 24.81 \% & 2.40(0.08) \\ & \\ 52.40 \% & 3.47(0.07) \\ 71.94 \% & 4.37(0.06)\end{array}$

Misinformation about the

Perpetrator

Rejection Rates

$1^{\text {st }}$ Misinformation

Scale: 0-100

Mean Confidence

$87.40 \%$

Scale: $1-5$

Rejection

(0.06)

Failure to Reject $\quad 1.96$

(0.26)

$2^{\text {nd }}$ Misinformation

$87.90 \%$

Rejection

(0.07)

Failure to Reject $\quad 2.24$

(0.32)

State of the Witness

Mean Agreement

Mean Confidence

Scale: $0-6$

Scale: $1-5$

Frightened

$1.07(0.13)$

$4.69(0.05)$

Tired

$1.48(0.15)$

$4.56(0.07)$

Preoccupied

$2.59(0.18)$

$4.55(0.07)$

Distracted

$2.45(0.16)$

$4.62(0.05)$

Unwell

$0.72(0.12)$

$4.74(0.05)$

Overall state (average)

$1.66(0.90)$

$4.63(0.04)$

\section{Memory Accuracy of the Perpetrator's Physical Characteristics and Behaviour}

A 3 (perpetrator's fine-grained characteristics, broad characteristics, and behaviour) X 2 (male and female witnesses) mixed factorial ANOVA was conducted on the percentage of items recollected from the staged crime scene. Male witnesses were more accurate than female witnesses, $F(1,172)=37.77$, $M S E=687.07, p<.001$, partial eta $^{2}=.180$. Overall, recollection was the lowest for fine-grained details and the highest for behaviours, $F(2,344)=341.94, M S E=$ 284.73, $p<.001$, partial eta ${ }^{2}=.665$. Yet, there was an interaction between type of information recollected and gender, $F(2,344)=20.03, M S E=284.73, p<.001$, partial eta $^{2}=.104$. Females' memory accuracy increased steadily from finegrained characteristics $(M=20.70 ; S E M=1.89)$ to broad characteristics $(M=$ 39.38; $S E M=2.34)$, and from the latter to behaviour $(M=68.86 ; S E M=2.18)$. Males' memory accuracy also doubled from fine-grained $(M=29.32 ; S E M=1.98)$ to broad characteristics $(M=66.67 ; S E M=2.45)$, but increased more modestly from the latter to behaviour $(M=75.30 ; S E M=2.28)$. 
Table 2. Participants' Responses to the Rehearsal Practice Questionnaire (Standard Error of the Mean in Parentheses)

Category of questions

(a) Frequency of Use of Rote Rehearsal in School (FRR)

Past Mean Frequency

Current Scale: $0-5$

(b) Breadth of Use of Rote Rehearsal (BRR) for Neither words \& $3.59(0.09)$ $3.30(0.10)$ sentences

Either words or sentences Both words \& sentences (c) Duration of Memories of Rote Rehearsal

Scale: $0-2$ $29.3 \%$ (DMRR)

(c) Opinion of Rote Rehearsal (ORR) Ineffective alone

$24.7 \%$ $46.0 \%$ Median Time

Scale: 0-9

A month

No opinion Scale: $-1-+2$ $30.5 \%$

Effective alone

$8.6 \%$

Effective with understanding

(d) Memorisation \& Recitation of the Holy $25.9 \%$ $35.1 \%$ Quran

$\begin{array}{ll}\begin{array}{l}\text { Amount of Memorisation } \\ \text { (AMQ) Scale: } 0-3\end{array} & \begin{array}{l}\text { Frequency of Recitation } \\ \text { (FRQ) Scale: } 0-3\end{array} \\ \text { None/I do not know } & \text { None/I do not know } \\ 14.9 \% & 10.9 \% \\ \text { Less than a part } & \text { Monthly or yearly } \\ 24.7 \% & 29.9 \% \\ \text { A part } & \text { Weekly } \\ 21.3 \% & 18.4 \% \\ \text { More than a part } & \text { Daily } \\ 39.1 \% & 40.8 \%\end{array}$

\section{Confidence in the Memories of the Perpetrator's Physical Characteristics and Behaviour}

A 3 (perpetrator's fine-grained characteristics, broad characteristics, and behaviour) $\mathrm{X} 2$ (male and female witnesses) mixed factorial ANOVA was conducted on the participants' confidence in their recollections of the staged crime scene. Male witnesses were more confident than female witnesses, $F(1,172)=$ 4.26, $M S E=1.72, p<.041$, partial eta ${ }^{2}=.024$. As for memory accuracy, confidence was the lowest for fine-grained details and the highest for behaviours, $F(2,344)=400.97, M S E=.43, p<.001$, partial eta ${ }^{2}=.700$. Yet, there was an interaction between type of information recollected and gender, $F(2,344)=3.69$, 
MSE $=.43, p=.026$, partial eta $^{2}=021$. Females' confidence increased approximately 1 point from fine-grained characteristics $(M=2.38 ; S E M=.11)$ to broad characteristics $(M=3.35 ; S E M=.10)$, but from the latter to behaviour the increase was rather modest $(M=4.17 ; S E M=.08)$. Males' confidence increased more uniformly from fine-grained $(M=2.42 ; S E M=.11)$ to broad characteristics $(M=3.60 ; S E M=.11)$, and from the latter to behaviour $(M=4.59 ; S E M=.08)$.

Spearman correlation coefficients, computed to assess the relationship between accuracy and confidence measures, indicated that confidence increased with accuracy of recollection, for fine-grained details $(r=+0.336, n=174, p<.05$, two tails), broad details ( $r=+0.337, n=174, p<.05$, two tails), and actions ( $r=$ $+0.274, n=174, p<.05$, two tails). However, the magnitude of the relationships, as indexed by coefficients of determination, was rather modest. Indeed, only a small percentage of the variance in memory accuracy predicted confidence $(11.29 \%, 11.36 \%$, and $7.51 \%$, respectively).

\section{Overall Memory Accuracy, Confidence, and State of the Witness}

Spearman correlation coefficients were computed to determine the extent to which the accuracy of and confidence in the identification of the perpetrator could be predicted by the state of the witness (see Table 3). As male and female witnesses did not display different patterns, correlation analyses were conducted including all participants' data. As expected, the more distracted were the witnesses, the less accurate were their recollections of the physical characteristics and behaviour of the perpetrator. Confidence also declined as distraction increased. Other states of the witness produced a similar pattern, but less consistently.

Table 3. Correlations between either Recollection Performance (Top Panel) or Confidence (Bottom Panel), and Self-Reported States of the Witnesses.

\begin{tabular}{|c|c|c|c|c|c|c|}
\hline $\begin{array}{l}\text { Recollection } \\
\text { Performance }\end{array}$ & Frightened & Tired & Preoccupied & Distracted & Unwell & $\begin{array}{l}\text { Overall } \\
\text { State }\end{array}$ \\
\hline$I P F C$ & --- & --- & -0.195 & -0.214 & --- & -0.254 \\
\hline$I P B C$ & -0.230 & --- & -0.156 & -0.294 & --- & -0.276 \\
\hline$I P B$ & -0.149 & --- & --- & -0.167 & -0.183 & -0.162 \\
\hline $\begin{array}{l}\text { Recollection } \\
\text { Confidence }\end{array}$ & & & & & & \\
\hline$I P F C$ & --- & --- & -0.215 & -0.299 & --- & -0.192 \\
\hline$I P B C$ & --- & -0.237 & -0.259 & -0.315 & --- & -0.314 \\
\hline$I P B$ & -0.220 & & -0.254 & -0.413 & --- & -0.403 \\
\hline
\end{tabular}

Interestingly, even for the average of the evaluations of witnesses' emotional and physical states (see last column), which was computed to serve as an overall measure of the attention devoted to the staged crime, correlations were significant, 
but weak. Namely, the degree of inattentiveness of the eyewitness did not predict much of the variance of memory accuracy and confidence (2.62\%-16.24\%).

\section{Overall Memory Accuracy, Confidence, and Rehearsal Practice}

Spearman correlation coefficients were also computed to determine the extent to which the accuracy of and confidence in the identification of the perpetrator's characteristics and actions could be predicted by the rehearsal practice data (see Table 4). No behavioural indices of rote rehearsal practice predicted memory accuracy. However, a favourable opinion about the effectiveness of rote rehearsal (ORR) selectively predicted participants' memory accuracy (i.e., records of the perpetrator's behaviour and his/her broad characteristics) and confidence (i.e., records of the perpetrator's broad and fine-grained characteristics). Participants' estimated duration of the memories that they created through rote rehearsal (DMRR) also predicted their confidence in their memories of the perpetrator's characteristics (both fine-grained and broad) and behaviour. The frequency of participants' reliance on memorisation in school (FRR), combining past (elementary school and high-school) and current (college) exposure, predicted confidence in memories of fine-grained characteristics. All significant correlations were positive, but weak. Indeed, only $2.37 \%-4.93 \%$ of the variance of memory accuracy or confidence was accounted by rote rehearsal measures.

Table 4. Correlations between either Recollection Performance (Top Panel) or Confidence (Bottom Panel) and Responses to the Rehearsal Practice Questionnaire

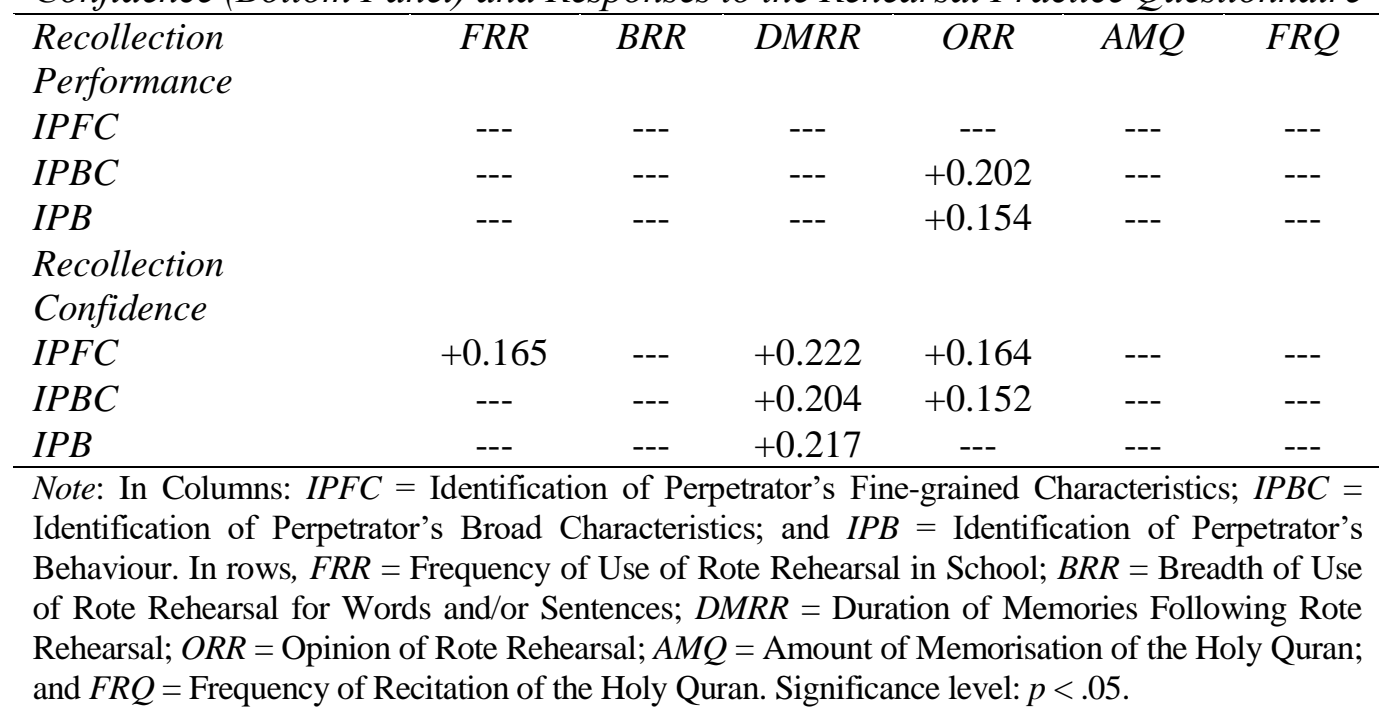

\section{Response to Misinformation as a Function of Memory Accuracy, Confidence, and Rote Rehearsal Practice}

Each participant's sensitivity to misleading information (i.e., his/her failing to reject at least one of the two misleading inquiries about the perpetrator's verbal 
behaviour) served as the dependent variable. Sensitivity to misleading information yielded no significant gender difference. Thus, data of males and females were combined to determine, through a one-way ANOVA, whether there were differences in memory accuracy and confidence between participants who fell for the suggestion (i.e., misinformation was treated as a real fact; $n=32$ ) and those who rejected it $(n=142)$. Greater memory accuracy for the perpetrator's broad characteristics was observed in participants who rejected the misleading information in the questionnaire $(M=55.40 ; S E M=2.13)$ than in participants who assimilated it into their memories $(M=39.06$; $S E M=4.50), F(1,172)=10.78$, $M S E=646.51, p=.001$, partial eta ${ }^{2}=.059$. Similarly, greater memory accuracy for the perpetrator's behaviour was observed in participants who rejected the misleading suggestion $(M=75.00 ; S E M=1.68)$ than in participants who assimilated it into their memories $(M=58.33$; $S E M=3.53), F(1,172)=18.15$, $M S E=399.71, p<.001$, partial eta ${ }^{2}=.095$. No difference in accuracy was observed in the recollections of fine-grained details, $F=1.82, n s$, since the same low rates were exhibited by those who rejected $(M=25.70 ; S E M=1.55)$ and those who failed to reject the misleading suggestion $(M=20.83 ; S E M=3.27)$. Instead, confidence was always greater for those who rejected it, irrespective of whether memory involved fine-grained details, $F(1,172)=8.49, M S E=1.01, p=.004$, partial eta ${ }^{2}=.047(M=2.51 ; S E M=.08$; versus $M=1.93 ; S E M=.18)$, broad characteristics, $F(1,172)=47.17, M S E=.77, p<.001$, partial eta ${ }^{2}=.215(M=$ $3.68 ; S E M=.07$; versus $M=2.51 ; S E M=.15)$, or behaviour, $F(1,172)=56.57$, $M S E=.46, p<.001$, partial eta $^{2}=.247(M=4.56 ;$ SEM $=.06$; versus $M=3.56$; $S E M=.12)$. Kruskall-Wallis did not uncover any difference between participants who rejected misinformation and those who failed to reject it in any of the queries regarding rote rehearsal practice, including performance $(a, b, \& d)$ and sentiment measures $(c), H \leq 2.47$, $n s$.

Could the group differences found in memory accuracy and confidence be attributed to differences in participants' overall attention devoted to the crime scene (as measured by the average of the witnesses' reported emotional and physical states)? Participants who rejected misinformation reported to be overall less distracted than those who failed to reject it, $F(1,172)=4.60, M S E=1.37, p$ $=.033$, partial eta ${ }^{2}=.026(M=1.57 ;$ SEM $=.10$, versus $M=2.09 ; S E M=.21)$. The gender differences reported above could also be traced to the overall attention devoted to the crime scene, $F(1,172)=18.09, M S E=1.27, p<.001$, partial eta ${ }^{2}$ $=.095$. In fact, females not only recollected fewer details of the crime scene than males and were less confident about their memory records, but also were overall more distracted $(M=2.01 ; S E M=.12)$ than males $(M=1.28 ; S E M=.12)$.

\section{Discussion}

The results of the present study can be summarised in four points: First, some central perceptual information of a crime (i.e., broad static details of the perpetrator and his/her behaviour) was more easily retained than other, similarly central, but fine-grained information. Interestingly, actions were better remembered 
than broad static details. In addition, as accuracy increased, confidence increased too. Other researchers, such as Migueles and García-Bajos, ${ }^{31}$ have also reported superior memory and confidence for central (i.e., integral to the main event observed) actions compared with central static details, irrespective of whether encoding was incidental or intentional. Thus, it is reasonable to assume that central information of eyewitnesses' records of a crime is most likely represented in memory as actions at the detriment of static details. This pattern of results suggests that eyewitnesses (including our participants) may have reconstructed the unexpected event to respond to queries by activating a mugging script in which actions are undoubtedly much more significant than static features. However, contrary to the results of Migueles and García-Bajos, ${ }^{32}$ the level of attention paid to the unexpected event did matter. In fact, in our study, as distraction increased, memory accuracy and confidence in the recollected information decreased, even though all encoding was incidental.

Second, individual differences in self-reported reliance on rote rehearsal practice, a performance measure, were not related to witnesses' accuracy and confidence of recollecting crime scenes. It is reasonable to assume that reliance on the practice of rote rehearsal may have benefits that are limited to the format in which the practice is exercised. If this is so, practicing rote rehearsal may benefit the acquisition and retention of verbal information (e.g., word lists and narratives), but does not generalise to information in other formats. Schmidt and Bjork ${ }^{33}$ have argued that an important ingredient for transfer of training between tasks is the overlap of the processes necessary for performance in the two tasks. However, this account of transfer, which relies on the commonality of processes, ${ }^{34}$ may be considered applicable only if certain conditions during the witnessing of the crime force the eyewitness to engage in processes that are also critical to performance in situations where he/she memorises and recites text. Besides differences in the format and complexity of the materials to encode, witnessing a crime unexpectedly is an incidental learning condition, whereby attention is suddenly and briefly captured by a fast-moving visual display. Key to effective encoding of the relevant information in the visual display is selective attention. Instead, practicing memorisation and recitation of verbal materials is an intentional learning condition whereby attention is deliberately directed towards a static visual display and is sustained for a continuous period of time. Thus, differences in content and processing may have hindered the transfer of the skills practiced in memorisation and recitation to witnessing a crime. Alternatively, if transfer is nevertheless feasible despite such differences, the benefits of practicing memorisation and recitation on memory performance involving visual scenes may be measurable only after a much more extensive exercise regimen than the one exhibited by our law students. Instances of extensive practice are found in ordinary memory experts, including waiters, ${ }^{35}$ taxi drivers, ${ }^{36}$ or exceptional experts, such as chess

\footnotetext{
${ }^{31}$ Migueles \& García-Bajos (1999).

${ }^{32}$ Migueles \& García-Bajos (1999).

${ }^{33}$ Schmidt \& Bjork (1992).

${ }^{34}$ Bransford, Franks, Morns \& Stein (1979).

${ }^{35}$ Bekinschtein, Cardozo \& Manes (2008); Ericsson \& Polson (1988).
} 
masters $^{37}$ and professional Vedic Sanskrit Pandits whose training involves memorisation and recitation of Sanskrit text for several hours a day with the goal of mastering the exact pronunciation and content of oral texts. ${ }^{38}$ Of course, the null finding regarding the relationship between memory accuracy and the frequency of the activities of memorisation and recitation (i.e., performance measures) may also be attributed to our study's reliance on self-reports. KSA is a country undergoing substantial economic and social changes. If there is a population who is aching for change, it is that of young adults of college age. ${ }^{39}$ Of particular interest for the purpose of our study are young Arabic-English bilingual individuals of college age (i.e., our participants), who are likely to experience two opposing influences in their daily lives, one reaffirming KSA's customs and traditions (which emphasise memorisation and recitation as practices) and the other endorsing Western values (which discount such practices as ineffective and outdated). Thus, it is entirely possible that the null finding regarding the relationship between memory accuracy and the frequency of memorisation and recitation is the accidental by-product of students underreporting use since memorisation and recitation conflict with their Western values, according to which critical analysis is prised and repetition is seen with suspicion.

Third, participants' views of rote rehearsal fell into three different categories: approximately $1 / 3$ of participants called it an ineffective strategy, $1 / 3$ saw it as effective alone, and 1/3 linked its effectiveness to semantic processing. Not surprisingly, memory accuracy and confidence for specific details increased with views of rote rehearsal practice combined with understanding. Furthermore, as estimates of the duration of memories developed through rote rehearsal practice increased so did confidence in the memories of central information of the crime scene. Important to know is that although the correlations found between memory performance and the views of rote rehearsal practice can be considered rather modest in magnitude, the direction of each significant relationship (positive) is noteworthy as it illustrates the extent to which views of a practice exercised in everyday life may be associated with witnesses' perceptual disposition to recollect accurately information from dynamic visual scenes. Confidence in the effectiveness of rote rehearsal practice and in the duration of the memories created through this practice may be also associated with a similar disposition. Yet, associations mostly concerned subjective views, such as sentiment and confidence, rather than objective performance. Although performance matters, sentiment is also relevant as it relates to motivation to engage in a specific activity. ${ }^{40}$ Thus, it is not surprising that a positive opinion about rote rehearsal (as a memory technique that can produce lasting memories, and as an effective memory tool if associated with understanding) predicted recollection performance of some central information as well as confidence in the information recollected.

\footnotetext{
${ }^{36}$ Maguire, et al. (2000).

${ }^{37}$ Chase \& Simon (1973); Gobet \& Simon (1996).

${ }^{38}$ Hartzell et al. (2016).

${ }^{39}$ Ménoret (2005); Murphy (2012).

${ }^{40}$ Hine, Maddox, Williams \& Carson (2004).
} 
Fourth, participants who were successful in rejecting misleading information exhibited superior recollection for details of the crime scene that involved either broad static characteristics or actions, and more confidence in their memories of all details. Yet, to a certain extent, these differences, as in the case of gender, could be the result of the overall attention devoted to the crime scene. In the memory literature, evidence indicates that males and females do not differ in their memory capacity, but rather in the type of information they remember, ${ }^{41}$ thereby implying differences in the attention paid to the variety of sources of information available in their environment. Not surprisingly, in the same literature, evidence exists that increased attention to visual details is associated with memory accuracy, including rejection of misleading information. ${ }^{42}$ Thus, our findings, albeit based on selfreports, support earlier findings of the role attentional processes play in encoding and later retrieval of relevant information.

The issue of individual differences in memory accuracy is particularly important in courts of law in KSA where the number of witnesses to a crime, their reputation ( $a d l$ ), and their concurring testimony play a considerable role in determining the culpability of a defendant. Because even minor discrepancies in eyewitnesses' testimonies make them invalid, a great deal of weight is given to the concurring nature of testimonies. ${ }^{43}$ However, agreement does not rule out confabulation induced by social influence. ${ }^{44}$ Most importantly, the reputation of witnesses can be considered a much less valid indicator of their reliance on facts than independent evidence of individual differences in memory accuracy, if such differences can be traced to specific quantifiable experiences, such as extensive practice with memorisation and recitation. Although no significant relationship was found between performance measures of rote rehearsal practice and memory accuracy in law students, differences in attention paid to an unexpected event, to some extent, appeared to account for individual differences in memory accuracy. Of course, a null finding is not to be interpreted as denial of the existence of a relationship. To further examine whether memory accuracy relates to students' use of memorisation and recitation as techniques for acquiring and preserving information, as well as for making information available to higher-order cognitive activities, such as critical analysis, students who are likely to rely on rote rehearsal even more than law students may need to be investigated. These are students whose major is Arabic and Islamic studies.

\section{List of References}

Ainsworth, P.B. (1981). 'Incident perception by British police officers' in Law and Human Behavior 5:231-236.

Bartlett, F.C. (1932). Remembering: An experimental and social study. Cambridge, UK: Cambridge University.

\footnotetext{
${ }^{41}$ Loftus, Banaji, Schooler \& Foster (1987).

${ }^{42}$ Baym \& Gonsalves (2010).

${ }^{43}$ Peters (2005).

${ }^{44}$ Ost, Ghonouie, Cook \& Vrij (2008).
} 
Baym, C.L. \& B.D. Gonsalves (2010). 'Comparison of neural activity that leads to true memories, false memories, and forgetting: An fMRI study of the misinformation effect' in Cognitive, Affective, \& Behavioral Neuroscience 10:339-348.

Bekinschtein, T.A., Cardozo, J. \& F.F. Manes (2008). 'Strategies of Buenos Aires waiters to Enhance memory capacity in a real-life setting' in Behavioral Neurology 20:65-70.

Bransford, J.D., Franks, J.J., Morns, C.D. \& B.S. Stein (1979). 'Some general constraints on learning and memory research.' In: L.S. Cermack \& F.I.M. Craik (eds.), Levels of processing in human memory, 331-354. Hillsdale, NJ: Erlbaum.

Chase, W.G. \& H.A. Simon (1973). 'Perception in chess' in Cognitive Psychology 4:5581.

Christianson, S.Å. \& E.F. Loftus (1987). 'Memory for traumatic events' in Applied Cognitive Psychology 1:225-239.

Clancy, S.A., McNally, R.J., Schacter, D. L., Lenzenweger, M.F. \& R.K. Pitman (2002). 'Memory distortion in people reporting abduction by aliens' in Journal of Abnormal Psychology 111:455-461.

DeKeyser, R. (2007). 'Skill acquisition theory.' In: B. Van Patten \& J. Williams (eds.), Theories in second language acquisition, 97-113. Mahwah, NJ: Lawrence Erlbaum.

Dunning, D. \& L.B. Stern (1992). 'Examining the generality of eyewitness hypermnesia: A close look at time delay and question type' in Applied Cognitive Psychology 6:643657.

Eisen, M.L., Morgan, D.Y. \& L. Mickes (2002). 'Individual differences in eyewitness memory and suggestibility: Examining relations between acquiescence, dissociation and resistance to misleading information' in Personality and Individual Differences 33:553-571.

Ericsson, K.A. \& P.G. Polson (1988). 'An experimental analysis of the mechanisms of a memory skill' in Journal of Experimental Psychology Learning, Memory, \& Cognition 14: 305-316.

Gade, A.M. (2004). Perfection Makes Practice: Learning, Emotion, and the Recited Quran in Indonesia. Honolulu, HI: University of Hawaii Press.

Gallo, D.A. (2010). 'False memories and fantastic beliefs: 15 years of the DRM illusion' in Memory \& Cognition 38:833-848.

Al-Ghazali A.H. (2011). The revival of religious sciences. Beirut, Lebanon: The House of Scientific Books. [In Arabic].

Gobet, F. \& H.A. Simon (1996). 'Recall of rapidly presented random chess positions is a function of skill' in Psychonomic Bulletin \& Review 3:159-163.

Günther, S. (2006). 'Be masters in that you teach and continue to learn: Medieval Muslim thinkers on educational theory' in Comparative Education Review 50:367-388.

Gutchess, A.H. \& D.L. Schacter (2012). 'The neural correlates of gist-based true and false recognition' in Neuroimage 59:3418-3426.

Hartzell, J.F., Davis, B., Melcher, D., Miceli, G., Jovicich, J., Nath, T., Singh N.C. \& U. Hasson (2016). 'Brains of verbal memory specialists show anatomical differences in language, memory and visual systems' in Neuroimage 131:181-192.

Hasher, L. \& R.T. Zacks (1979). 'Automatic and effortful processes in memory' in Journal of Experimental Psychology: General 108:356-388.

Hine, F.R., Maddox, G.L., Williams, R.B. \& R.C. Carson (2004). 'Definitions and conceptual orientations.' In: F.R. Hine, R.C Carson, G.L. Maddox, R.J.J. Thompson, \& R.B. Williams, (eds.), Introduction to Behavioral Science in Medicine, 139-151. Springer, New York, NY.

Hintzman, D.L. (1976). 'Repetition and memory' in Psychology of Learning and Motivation 10:47-91. 
Hirst, W., Phelps, E.A., Buckner, R. L., Budson, A.E., Cuc, A., Gabrieli, J.D., Johnson, M.K.,Lyle, K.B., Lustig, C., Mather, M., Meksin, R., Mitchell, K.J., Ochsner, K.N., Schacter, D.L., Simons, J.S. \& C.J. Vaidya (2009). 'Long-term memory for the terrorist attack of September 11: flashbulb memories, event memories, and the factors that influence their retention' in Journal of Experimental Psychology: General 138:161-176.

Iqbal, J. \& Ahmad, A. (2015). 'Effect of extensive rote learning experience on subsequent academic achievement' in Pakistan Armed Forces Medical Journal 65:510-514.

Kassin, S.M., Tubb, V.A., Hosch, H.M. \& A. Memon (2001). 'On the" general acceptance" of eyewitness testimony research: A new survey of the experts' in American Psychologist 56:405-416.

Kuhl, B.A., Shah, A.T., DuBrow, S. \& Wagner, A.D. (2010). 'Resistance to forgetting associated with hippocampus-mediated reactivation during new learning.' in Nature Neuroscience 13:501-506.

Lacy, J.W. \& C.E. Stark (2013). 'The neuroscience of memory: implications for the courtroom' in Nature Reviews Neuroscience 14:649-658.

Loftus, E.F. (2003). 'Make-believe memories' in American Psychologist 58:867-873.

Loftus, E.F., Banaji, M.R., Schooler, J.W. \& R.A. Foster (1987). 'Who remembers what? Gender differences in memory' in Michigan Quarterly Review 26:64-85.

Loftus, E.F. \& T.E. Burns (1982). 'Mental shock can produce retrograde amnesia' in Memory \& Cognition 10:318-323.

Loftus, E.F., Levidow, B. \& S. Duensing (1992). 'Who remembers best? Individual differences in memory for events that occurred in a science museum' in Applied Cognitive Psychology 6:93-107.

Maguire, E.A., Gadian, D.G., Johnsrude, I.S., Good, C.D., Ashburner, J., Frackowiak, R. S.J. \& C.D. Frith (2000). 'Navigation-related structural change in the hippocampi of taxi drivers' in Proceedings of the National Academy of Sciences 97:4398-4403.

Ménoret, P. (2005). The Saudi enigma: a history. London, UK: Zed Books.

Meyersburg, C.A., Bogdan, R., Gallo, D.A. \& R.J. McNally (2009). 'False memory propensity in people reporting recovered memories of past lives' in Journal of Abnormal Psychology 118:399-404.

Migueles, M. \& E. Garcia-Bajos (1999). 'Recall, recognition, and confidence patterns in eyewitness testimony' in Applied Cognitive Psychology 13:257-268.

Mills, A. \& S.J. Lynn (2000). Past-life experiences. In E. Cardena, S.J. Lynn, \& S. Krippner (eds.), Varieties of anomalous experience: Examining the scientific evidence, 283-313. Washington, DC: American Psychological Association

Murphy, C. (2012). A Kingdom's future: Saudi Arabia through the eyes of its

twentysomethings. Washington, DC: Woodrow Wilson International Center for Scholars, Middle East Program.

Odinot, G., Wolters, G. \& P.J. van Koppen (2009). 'Eyewitness memory of a supermarket robbery: A case study of accuracy and confidence after 3 months' in Law and Human Behaviour 33:506-514.

Ost, J., Ghonouie, H., Cook, L. \& A. Vrij (2008). 'The effects of confederate influence and confidence on the accuracy of crime judgments' in Acta Psychologica 128:25-32.

Paris, D.C. (1997). 'School reform: Too much talk, too little action.' Forum for Applied Research and Public Policy 12:46-56.

Peters, R. (2005). Crime and punishment in Islamic law: Theory and practice from the sixteenth to the twenty-first century No. 2. Cambridge, UK: Cambridge University Press. 
Rissman, J., Greely, H.T. \& A.D. Wagner (2010). 'Detecting individual memories through the neural decoding of memory states and past experience.' Proceedings of the National Academy of Sciences 107:9849-9854.

Roche, R.A., Mullally, S.L., McNulty, J.P., Hayden, J., Brennan, P., Doherty, C.P., Fitzsimons, M., McMackin, D., Prendergast, J., Sukumaran, S., Mangaoang, M.A., Robertson, I.H. \& S.M. O'Mara (2009). 'Prolonged rote learning produces delayed memory facilitation and metabolic changes in the hippocampus of the ageing human brain' in BMC Neuroscience 10:136-153.

Scarborough, D.L., Gerard, L. \& C. Cortese (1979). 'Accessing lexical memory: The transfer of word repetition effects across task and modality' in Memory \& Cognition 7:3-12.

Schmidt, R.A. \& R.A. Bjork (1992). 'New conceptualizations of practice: Common principles in three paradigms suggest new concepts for training.' Psychological Science 3:207-218.

Schwarz, K.A. \& C. Büchel (2015). 'Cognition and the Placebo Effect - Dissociating Subjective Perception and Actual Performance' in PLoS ONE 10: e0130492.

Scrivner, E. \& M.A. Safer (1988). 'Eyewitnesses show hypermnesia for details about a violent event' in Journal of Applied Psychology 73:371-377.

Simons, D.J. \& C.F. Chabris (2011). 'What people believe about how memory works: A representative survey of the US population' in PloS ONE 6:e22757.

Slotnick, S.D. \& D.L. Schacter (2004). 'A sensory signature that distinguishes true from false memories' in Nature Neuroscience 7:664-672.

Stark, C.E., Okado, Y. \& E.F. Loftus (2010). 'Imaging the reconstruction of true and false memories using sensory reactivation and the misinformation paradigms' in Learning \& Memory 17:485-488.

Tickner, A.H. \& E.C. Poulton (1975). 'Watching for people and actions' in Ergonomics 18:35-51.

Turtle, J.W. \& J.C. Yuille (1994). 'Lost but not forgotten details: Repeated eyewitness recall leads to reminiscence but not hypermnesia' in Journal of Applied Psychology 79:260-271.

Valenzuela, M. J. Jones, M., Rae, W.W.C., Graham, S., Shnier, R. \& P. Sachdev (2003). 'Memory training alters hippocampal neurochemistry in healthy elderly' in Neuroreport 14:1333-1337.

Wells, G.L. (1993). 'What do we know about eyewitness identification?' in American Psychologist 48:553-571.

Wells, G.L. \& E.A. Olson (2003). 'Eyewitness testimony' in Annual Review of Psychology 54:277-295.

Wiltgen, B.J. \& A.J. Silva (2007). 'Memory for context becomes less specific with time' in Learning \& Memory 14:313-317.

Winocur, G., Moscovitch, M. \& M. Sekeres (2007). 'Memory consolidation or transformation: context manipulation and hippocampal representations of memory' in Nature Neuroscience 10:555-557.

Yuille, J. C. (1984). 'Research and teaching with police: A Canadian example' in Applied Psychology 33:5-22. 